\title{
Pesquisa em Educação: desafios contemporâneos
}

\author{
Marli Eliza Dalmazo Afonso de André ${ }^{1}$ \\ Pontifícia Universidade Católica de São Paulo
}

resumo $O$ texto objetiva discutir questões epistemológicas e metodológicas relacionadas à pesquisa em educação. Descreve brevemente a trajetória da pesquisa educacional no Brasil e aponta o grande crescimento de trabalhos nos últimos 20 anos, acompanhado de muitas mudanças nos temas, enfoques, metodologias e contextos das pesquisas. Destaca questões referentes à natureza dos conhecimentos produzidos, aos critérios utilizados para julgar a pesquisa e aos pressupostos dos métodos quantitativos e qualitativos. Conclui mostrando as precárias condições de produção do trabalho científico tanto para os discentes quanto para os docentes e enumera alguns desafios a serem enfrentados.

palavras-chave: pesquisa em educação, qualidade da pesquisa, condições de produção do conhecimento

abstract The paper aims at discussing epistemological and methodological issues in educational research. First, it describes historical path of Brazilian educational research and shows that a growth in the number of studies in the last 20 years brought out a great change in topics, methodologies, theoretical frameworks, and contexts. Next, it points out the main problems that have been raised concerning quality of research, such as the nature of produced knowledge, the criteria for research evaluation and the underlined assumptions of quantitative and qualitative methodologies.

${ }^{1}$ marliandre@pucsp.br. 
key words: educational research, research quality, conditions for scientific knowledge production

\section{Introdução}

Para entender a situação atual da pesquisa na área de educação, é preciso recompor sua trajetória, de modo que possamos situar seus avanços e desafios contemporâneos.

O que o exame da trajetória da pesquisa educacional nos revela? Segundo Angelucci e al. (2004, p. 53), a pesquisa educacional nasce de uma iniciativa governamental. Em 1938 foi criado o INEP (Instituto Nacional de Estudos Pedagógicos) no Ministério de Educação e Cultura, que vai apoiar o desenvolvimento de estudos e pesquisas para subsidiar a política educacional. A relação entre a pesquisa e a política de educação era compreendida em termos estritamente instrumentais: "cabia aos pesquisadores trazer subsídios práticos à formulação e avaliação de ações oficiais no campo da educação escolar". A característica básica desse primeiro momento da pesquisa educacional era a forte influência da psicologia na análise das questões de ensino e aprendizagem. As idéias pedagógicas eram marcadas pelo escolanovismo, que, fundamentado na pedagogia científica, na biologia e na psicologia, defendia o ensino centrado no aluno e valorizava o aprender a aprender.

Com o início da publicação da Revista Brasileira de Estudos Pedagógicos do INEP, em 1944, houve possibilidade de divulgação sistemática de trabalhos científicos da área.

O segundo momento da pesquisa educacional tem seu marco na criação do Centro Brasileiro de Pesquisa Educacional em 1956 e de cinco centros regionais, vinculados ao INEP. "Novamente a pesquisa como meio privilegiado para atingir fins governamentais. No interior da ideologia nacional-desenvolvimentista muda, no entanto, o objeto: agora se trata de mapear a sociedade brasileira de modo a fornecer dados a uma política educacional que alavancasse o progresso econômico do país, levando em conta as diferenças regionais... Era a 
vez das ciências sociais, em chave teórica funcionalista" (Angelucci et al. 2004, p. 53-54).

Mas só no final da década de 60 e início dos anos 70, com a expansão dos quadros das universidades e principalmente com a implantação dos cursos de pós-graduação, é que se dá a institucionalização da pesquisa. Em 1965 foi criado o primeiro curso de pós-graduação em educação na PUC/RJ. Entre 1971 e 1972 foram criados 10 cursos e em 1975 já havia 16. Intensifica-se a formação de recursos humanos no exterior e no retorno desses professores para integrar os programas de pós-graduação; têm-se, como diz Gatti (1983, p.4) "as condições institucionais nas quais prioritariamente a pesquisa em educação e a formação de seus recursos humanos se fará a partir de então".

Esse breve exame das origens da pesquisa na área de educação mostra que ela não nasceu de um movimento das próprias universidades, mas foi induzida pelos órgãos governamentais segundo expectativas muito definidas: dar subsídios às ações governamentais. Sua evolução, no entanto, é marcada pela estreita vinculação aos cursos de pós-graduação, o que faz com que ela fique durante muito tempo restrita a esse âmbito. Só muito recentemente algumas instituições, especialmente as públicas e algumas comunitárias, talvez por uma certa pressão externa, se empenharam na criação de grupos de pesquisa fora do espaço da pós-graduação.

Embora a história da pesquisa educacional no nosso país seja relativamente curta, a produção científica da área vem crescendo substantivamente e se diversificando, a ponto de permitir um olhar crítico sobre seus avanços e suas perspectivas.

\section{Muitas Mudanças, Alguns Avanços}

Ao mesmo tempo em que se observa um crescimento muito grande no número de pesquisas da área de educação nos últimos 20 anos, decorrente principalmente da expansão da pós-graduação, observam-se também muitas mudanças nos temas e problemas, nos 
referenciais teóricos, nas abordagens metodológicas e nos contextos de produção dos trabalhos científicos.

Os temas se ampliam e diversificam. Os estudos que nas décadas de 60-70 se centravam na análise das variáveis de contexto e no seu impacto sobre o produto, nos anos 80 vão sendo substituídos pelos que investigam sobretudo o processo. Das preocupações com o peso dos fatores extra-escolares no desempenho de alunos, passa-se a dar uma maior atenção ao peso dos fatores intra-escolares: é o momento em que aparecem os estudos que se debruçam sobre o cotidiano escolar, focalizam o currículo, as interações sociais na escola, as formas de organização do trabalho pedagógico, a aprendizagem da leitura e da escrita, a disciplina e as relações de sala de aula, a avaliação. $\mathrm{O}$ exame de questões gerais, quase universais, vai dando lugar a análises de problemáticas locais, investigadas em seu contexto específico.

Os enfoques também se ampliam e diversificam. Como afirma Gatti (2000), a propagação da metodologia de pesquisa-ação e da teoria do conflito no início dos anos 80 , ao lado de um certo descrédito de que as soluções técnicas iriam resolver os problemas da educação brasileira, faz mudar o perfil da pesquisa educacional, abrindo espaço a abordagens críticas. Recorre-se não mais exclusivamente à psicologia ou à sociologia, mas à antropologia, à história, à lingüística, à filosofia. Constata-se que para compreender e interpretar grande parte das questões e problemas da área de educação é preciso recorrer a enfoques multi/inter/transdisciplinares e a tratamentos multidimensionais. Pode-se afirmar que há um consenso sobre os limites que uma única perspectiva ou área de conhecimento apresentam para a devida exploração e para um conhecimento satisfatório dos problemas educacionais.

$\mathrm{Se}$ os temas e referenciais se diversificam e se tornam mais complexos nos anos 80-90, as abordagens metodológicas também acompanham essas mudanças. Ganham força os estudos "qualitativos", que englobam um conjunto heterogêneo de métodos, de técnicas e de análises, que vão desde os estudos antropológicos e etnográficos, as pesquisas participantes, os estudos de caso até a pesquisa-ação e as análises de discurso, de narrativas, de histórias de vida. 
As duas últimas décadas também assistiram a uma mudança no contexto de produção dos trabalhos de pesquisa. Embora a grande maioria dos estudos continue sendo produzida nos programas de pósgraduação stricto sensu, as temáticas privilegiadas e as formas de desenvolvimentos desses estudos vêm sofrendo mudanças. Se nas décadas de 60-70 o interesse se localizava nas situações controladas de experimentação, do tipo laboratório, nas décadas de 80-90 o exame de situações "reais" do cotidiano da escola e da sala de aula é que constituiu a principal preocupação do pesquisador. Se o papel do pesquisador era sobremaneira o de um sujeito "de fora", nos últimos anos tem havido uma grande valorização do olhar "de dentro", fazendo surgir muitos trabalhos em que se analisa a experiência do próprio pesquisador ou em que o pesquisador desenvolve a pesquisa em colaboração com os participantes.

Essas novas modalidades de investigação suscitam o questionamento dos instrumentais teórico-metodológicos disponíveis e dos parâmetros usuais para o julgamento da qualidade do trabalho científico. Extrapolam o campo da educação, encorajando o diálogo entre especialistas de diferentes áreas do conhecimento, com diferentes bagagens de experiência e diferentes graus de inserção na prática profissional.

\section{Questões sobre os Fins}

A diversidade de temáticas, enfoques, métodos e contextos trouxe, naturalmente, problemas de diferentes ordens para a pesquisa em educação, entre os quais podemos destacar:

a) questões referentes aos fins da investigação e à natureza dos conhecimentos produzidos. O que caracteriza um trabalho científico? Qual a relação entre conhecimentos científicos e outros tipos de conhecimento?

b) questões relativas aos critérios de avaliação dos trabalhos científicos. Como julgar o que é uma boa pesquisa? Quem define esses critérios? 
c) questões voltadas aos pressupostos dos métodos e técnicas de investigação, tanto nas abordagens qualitativas quanto nas quantitativas. Como se desenvolve um estudo de caso etnográfico? Quais os principais cuidados numa pesquisa-ação? Como elaborar instrumentos válidos e fidedignos? Quando é possível generalizar os resultados?

Tomemos alguns aspectos desses três grupos de questões.

Qual é - ou deve ser - o propósito da pesquisa? Para que ou para quem se deve produzir os conhecimentos? Essas são questões que têm estado presente nos debates acadêmicos e podem ser encontradas em diversas revisões críticas da pesquisa educacional.

Se para alguns a pesquisa objetiva a geração de conhecimentos (novos?), gerais, organizados, válidos e transmissíveis, para outros ela busca o questionamento sistemático, crítico e criativo. Se alguns centram sua atenção no processo de desenvolvimento da pesquisa e no tipo de conhecimento que está sendo gerado, outros se preocupam mais com os achados das pesquisas, sua aplicabilidade ou seu impacto social.

Em um balanço recente da pesquisa em educação, Gatti (2000) nos fala de uma tendência dos trabalhos da área para um pragmatismo imediatista, tanto na escolha dos problemas quanto na preocupação com uma aplicabilidade direta dos resultados. Embora reconhecendo a necessária origem social dos temas e problemas da pesquisa em educação e a importância das questões que no imediato são carentes de análise e proposições, ela nos alerta para a tendência do recorte excessivamente limitado e para as análises circunscritas aos aspectos aparentes dos problemas, deixando de lado as perguntas mais de fundo e de espectro mais amplo. Segundo ela, a pesquisa "não pode estar a serviço de solucionar pequenos impasses do cotidiano, porque ela, por sua natureza e processo de construção parece não se prestar a isso, uma vez que o tempo de investigação científica, em geral, não se coaduna com as necessidades de decisões mais rápidas". E continua: "a busca da pergunta adequada, da questão que não tem resposta evidente é que constitui o ponto de origem de uma investigação científica" e nem sempre é o que se encontra na produção da área. 
Há dez anos, encontramos considerações similares numa revisão de pesquisas da pós-graduação em educação feita por Mirian Warde (1990). Ela afirma que "apesar dos esforços em superar a visão estreitamente técnica e administrativa que herdamos dos intelectuaisdirigentes escolanovistas, mantemos em nossa área uma tônica técnicoadministrativa, de um tal jeito que parece-nos estar sempre produzindo com vistas à aplicabilidade" (p.72). Temos, segunda ela, uma preocupação pragmática que nos leva sempre a "justificar que, apesar das aparências em contrário, o que estamos produzindo tem, em última instância, uma utilidade social" (p.72). E ela conclui: "Não é casual que tenhamos substituído, no discurso, o critério de relevância científica (em razão de sua dubiedade política e ideológica) pelo ainda mais duvidoso critério de relevância social. Continuamos pragmatistas, mas agora em nome do coletivo!” (p.72).

Outra pesquisadora que traz posições provocativas e instigantes nessa discussão é Marília G. Miranda (2000) ao focalizar o tema da articulação ensino e pesquisa, no debate contemporâneo sobre a formação dos professores e mais especificamente se centrando na literatura referente ao professor reflexivo/pesquisador. Segundo Miranda, a literatura sobre o professor reflexivo/pesquisador suscita questões relativas às relações entre o conhecimento acadêmico e o conhecimento dos práticos, fazendo uma crítica pesada ao elitismo da Universidade. Essa literatura, segundo ela, tem vários méritos: (a) valorizar a ação do professor como caminho para sua autonomia e emancipação; (b) buscar propósitos justos e generosos ao dar voz ao professor para melhorar a prática, combater as desigualdades e a exclusão; (c) fazer uma crítica salutar às universidades e às suas relações com os práticos. A preocupação da autora, no entanto, é com a possível adoção acrítica dessa perspectiva, o que pode causar sérios problemas, como: (a) converter-se numa retórica legitimadora da reforma educacional pondo nos ombros do professor toda a responsabilidade pelo seu insucesso; (b) ao insistir num processo de reflexão orientado para resolver problemas imediatos da prática, pode confirmar uma prática adaptativa aos problemas e não transformadora; (c) "ao negar a teoria como parte necessária do processo de autonomia 
não estaria reduzindo, em lugar de elevar, as reais possibilidades de reflexão crítica do professor?"; (d) o suposto de que o conhecimento é importante porque útil e imediatamente aplicável à prática não estaria afastando o professor de uma reflexão teórica que não esteja orientada para um fim imediato?; (e) corre-se o risco de desqualificar a universidade como instância formadora de professores; (f) "pode-se converter o exercício da pesquisa em ação esvaziada de significados se não the for garantida uma formação teórica sólida, preocupada não com os aspectos imediatos da vida escolar, mas também com outras grandes questões da cultura e da sociedade contemporânea (p.9). Segundo ela, "sem teoria não há emancipação" (p.9).

Partilhamos de muitas das preocupações de Marília G. Miranda, pois temos visto surgir, nos últimos anos, uma tendência de apoio incondicional aos estudos que envolvem algum tipo de intervenção, aliada a uma crítica veemente ao caráter distante e acadêmico dos estudos produzidos na Universidade. No fundo dessa polêmica está uma supervalorização da prática e um certo desprezo pela teoria.

Com experiência nesse tipo de pesquisa, percebo quão difícil é conciliar os papéis de ator e de pesquisador, buscando o equilíbrio entre a ação e a investigação, pois o risco é sempre muito grande de sucumbir ao fascínio da ação, deixando para o segundo plano a busca do rigor que qualquer tipo de pesquisa requer.

Um texto publicado por Gary Anderson e Kathryn Herr no Educational Researcher de junho/julho de 99 mostra muito claramente como nos Estados Unidos essa onda do professor reflexivo vem sendo apropriada por algumas Faculdades de Educação sem a devida preocupação com a manutenção do rigor. Segundo esses mesmos autores, os programas que objetivam formar o professor reflexivo por intermédio da pesquisa-ação não podem ser julgados pelos mesmos critérios de validade das pesquisas positivistas nem das pesquisas naturalistas, mas exigem uma nova definição de rigor. Segundo eles, muitas faculdades de educação que embarcam nessa onda têm pouca clareza sobre o que significa desenvolver um programa rigoroso que tenha como foco principal o conhecimento dos práticos. Eles argumentam que os critérios de julgamento da pesquisa acadêmica 
tradicional precisam ser criticados e substituídos por outros, mais adequados. Os autores sugerem então um conjunto de critérios para julgar esse tipo de pesquisa: validade externa, que diz respeito ao valor dos resultados alcançados em função do projeto; validade de processo refere-se aos métodos e técnicas utilizadas, assim como às evidências obtidas para sustentar as afirmações feitas; validade democrática, que indaga se as múltiplas perspectivas e interesses dos participantes foram contemplados; validade catalítica, que leva os participantes a conhecer melhor a realidade para transformá-la; validade dialógica, que consiste na busca do diálogo com os pares para discussão do problema e dos resultados da pesquisa.

\section{Como se define o que é uma boa pesquisa?}

Uma segunda ordem de problemas da pesquisa em educação é a que diz respeito aos critérios de julgamento dos trabalhos científicos. A crítica aos estudos de cunho positivista levou a uma rejeição aos critérios então utilizados para avaliar esses trabalhos. A literatura sobre as abordagens qualitativas trouxe um rol de critérios alternativos, alguns se contrapondo aos já conhecidos e respeitados: a plausibilidade substitui a validade, a credibilidade surge no lugar da fidedignidade e a "transferência" é usada para se contrapor à generalização (Lincoln e Guba, 1985). Ao lado desses, são propostos outros critérios, como a triangulação - de métodos, sujeitos, perspectivas -, a validação pelos pares (Dawson, 1982) e a generalização naturalística (Stake, 1978).

Mas seriam esses critérios aplicáveis a todos os tipos de pesquisa? Ou existiriam alguns mais gerais e outros que se diversificariam segundo o tipo de pesquisa? Tendo a responder positivamente à segunda questão e acrescento que a construção desses critérios, tanto os mais gerais quanto os mais específicos, é uma tarefa coletiva e de longo prazo. Nesse momento, o que podemos fazer é tentar explicitar os critérios que temos seguido para avaliar, por exemplo, os projetos do CNPq ou da FAPESP e o que temos levado em conta ao examinar os trabalhos dos pós-graduandos nas bancas. 
Temos destacado a importância de que os trabalhos atendam aos critérios de relevância científica e social, ou seja, estejam inseridos num quadro teórico em que fique evidente sua contribuição ao conhecimento já disponível. Temos valorizado a opção de temas engajados na prática social. Temos cobrado das pesquisas que tenham um objeto bem definido, que os objetivos ou questões sejam claramente formulados, que a metodologia seja adequada aos objetivos e os procedimentos metodológicos suficientemente descritos e justificados. A análise deve ser densa, fundamentada, trazendo as evidências ou as provas das afirmações e conclusões. Deve ficar evidente o avanço do conhecimento, ou seja, o que cada estudo acrescenta ao já conhecido ou sabido.

Nos estudos do tipo etnográfico temos enfatizado a necessidade de apreensão da perspectiva do outro, o uso da teoria na construção das categorias e a articulação entre o particular e o geral, entre o micro e o macrossocial.

$\mathrm{Na}$ pesquisa-ação temos destacado a necessidade do tratamento adequado da subjetividade e a clara explicitação do que seja ação e do que seja pesquisa, bem como a consideração das questões éticas. Temos alertado que devem ser explicitados os mecanismos de controle da subjetividade, que devem ser muito bem definidos os papéis e discutidos os graus de participação dos vários atores envolvidos na pesquisa. Além disso, temos enfatizado a questão da autoria: quem fará e como será feita a divulgação dos dados? Sob que forma e onde serão apresentados? Quem serão os autores?

Ainda como contribuição para o debate sobre os critérios de avaliação da pesquisa, trago as provocações de J. Beillerot na revista Recherche et Formation $n^{0} 9$ de 1991, cujo texto foi traduzido num capítulo do livro $O$ papel da pesquisa na formação e na prática dos professores. (André, 2002). Segundo esse autor, há três condições básicas para que se possa considerar a existência de uma pesquisa: a) produção de conhecimentos novos; b) procedimentos rigorosos; c) comunicação dos resultados. Cabe à comunidade científica julgar se os conhecimentos acrescentam algo ao já conhecido, ou seja, se são conhecimentos novos. A utilização de instrumentos e procedimentos 
cuidadosamente planejados e implementados seria um critério indiscutível para qualquer tipo de pesquisa. A divulgação dos resultados seria uma condição essencial para que a comunidade pudesse julgar o valor dos conhecimentos produzidos. Há ainda uma segunda ordem de critérios, que seriam complementares: d) perspectiva crítica a respeito das fontes, dos métodos e dos modos de trabalho utilizados pelo pesquisador; e) controle e sistematização na coleta de dados; f) presença de interpretações segundo teorias reconhecidas e atuais que permitam elaborar uma problemática de discussão.

Esses critérios, embora elaborados no contexto da pesquisa educacional francesa, nos parecem muito interessantes $\mathrm{e}$ suficientemente provocativos para uma discussão sobre quais critérios devem ser usados no julgamento das pesquisas em educação.

\section{Questões Metodológicas}

Várias revisões de pesquisas da área de educação (André, 2000; Carvalho, 1998; Gatti, 2000; Warde, 1993) têm apontado a fragilidade metodológica dos estudos e pesquisas, que tomam porções muito reduzidas da realidade, um número muito limitado de observações e de sujeitos, levantamentos de opiniões com instrumentos precários, análises pouco fundamentadas e interpretações sem respaldo teórico. Isso é válido tanto nos estudos do tipo survey quanto nas abordagens qualitativas. Nos estudos de grandes amostras e dados quantitativos surgem várias questões, muito bem sintetizadas por Gatti (2000):

verificamos hipóteses mal colocadas, variáveis pouco operacionalizadas ou operacionalizadas de modo inadequado, quase nenhuma preocupação com a validade e a fidedignidade dos instrumentos de medida, variáveis tomadas como independentes sem o serem, modelos estatísticos aplicados a medidas que não suportam suas exigências básicas, por exemplo de continuidade, intervalaridade, proporcionalidade...(p.12) 
A autora também resume muito adequadamente os problemas encontrados nos estudos "qualitativos":

observações casuísticas, sem parâmetros teóricos, a descrição do óbvio, análises de conteúdo realizadas sem metodologia clara, incapacidade de reconstrução do dado e de percepção crítica dos vieses situacionais, desconhecimento no trato da história e de estórias, precariedade na documentação e na análise documental. (p. 12)

A esses problemas eu acrescentaria outros que venho detectando numa revisão de estudos que abordam o tema da formação docente e que tendem mais recentemente a usar a pesquisa-ação: há freqüentemente uma certa confusão entre o que seja ação formativa e pesquisa-ação, entre o papel do pesquisador e o papel dos participantes, entre ensino e pesquisa, ação e investigação.

Esses pontos merecem séria consideração, principalmente por parte dos orientadores dos diversos programas de pós-graduação do país, pois são problemas que foram localizados numa análise das dissertações e teses produzidas nos anos 90 .

\section{Condições de Produção do Conhecimento}

Ao focalizar a situação atual da pesquisa em educação não podemos deixar de considerar as condições reais de produção do conhecimento. Afinal, em que condições trabalham os pesquisadores? Quais os recursos de que dispõem os pós-graduandos para desenvolver seus estudos e pesquisas? E os docentes?

Focalizando as condições de que dispõem os discentes, temos que separar mestrandos e doutorandos. No caso dos mestrandos, o tempo de titulação é muito curto. É possível formar um pesquisador em dois anos ou dois anos e meio? Não estaríamos comprometendo a qualidade da produção científica ao fixar um tempo tão curto? É verdade que alguns mestrandos passaram pela Iniciação Científica e aí se nota a grande diferença, pois isso os faz seguir mais rápido e, em geral, com um nível de qualidade superior aos que não tiveram a 
mesma experiência. Mas esse programa de Iniciação abrange ainda um número muito reduzido de alunos, o que torna seu impacto também reduzido. A grande maioria não dispõe de bolsa, trabalha ao mesmo tempo em que faz o mestrado e não tem quase nenhuma experiência de iniciação à pesquisa.

No caso dos doutorandos, o tempo de titulação é maior, o número de disciplinas, em geral, é menor do que para os mestrandos, todos já têm alguma experiência de pesquisa, nem que seja só a do mestrado, o que lhes dá melhores condições, aparentemente, para produzir bons trabalhos. Entretanto, percebe-se também que encontram dificuldades, seja porque lhes faltam condições concretas, já que muitos mantêm sua atividade profissional, o que os faz permanecer em seus locais de origem e gastar tempo e dinheiro em viagens, seja porque os programas de doutorado não oferecem atividades que os ajudem a realizar trabalhos com densidade teórica e cuidado metodológico. Por exemplo, o envolvimento em grupos de pesquisa poderia não só trazer uma rica contribuição na formação do pesquisador, mas permitir a consolidação de linhas de pesquisa, o que certamente reduziria as temáticas fragmentadas muito comuns e freqüentemente criticadas na área. No entanto, só muito recentemente os programas de pós-graduação passaram a se preocupar com a organização e o funcionamento de grupos de pesquisa. Mesmo assim, os docentes lutam com muita dificuldade para conseguir as condições mínimas de espaço, de tempo e de recursos materiais e humanos para efetivar esse trabalho.

No caso dos docentes, a situação não muda muito. Houve, sem dúvida, nos últimos 10 anos, mudança nas condições de desenvolvimento da pesquisa em educação no Brasil. A começar pelos financiamentos que vêm minguando. Se nos anos 80 a FINEP (Financiadora de Projetos/MCT) e o INEP davam apoio a pesquisas da área, nos anos mais recentes esse apoio quase foi extinto. Temos as Fundações Estaduais de Pesquisa, mas também temos hoje um número muito maior de pesquisadores qualificados para solicitar financiamento, o que aumenta a competição. Além disso, as Fundações nem sempre distribuem igualmente seus recursos entre as diversas 
áreas de conhecimento porque os membros da comunidade científica que julgam as prioridades não raramente consideram a área de educação menos científica do que outras.

Mais grave do que a redução dos financiamentos foi a subtração acentuada do nosso tempo crítico, nos últimos anos. Os docentes estão cada vez mais sobrecarregados com aulas, comissões, reuniões, pareceres, trabalhos de alunos para ler e avaliar, sobrando muito pouco tempo para a produção intelectual, para a reflexão, para a crítica e para o tão necessário aprofundamento dos trabalhos. Como produzir trabalhos de qualidade em condições tão adversas?

\section{Os Desafios}

Nesse cenário, antevemos alguns desafios e perspectivas:

a) assumir seriamente, como tarefa coletiva, o estabelecimento de critérios para avaliar as pesquisas da área. Apresentá-los publicamente, ouvir as críticas e sugestões, mantendo um debate constante sobre eles;

b) defender a qualidade dos trabalhos e a busca do rigor; conhecimento;

c) lutar pela melhoria das condições de produção do

d) construir espaços coletivos nos programas de pós-graduação para elaboração de projetos e desenvolvimento de pesquisas.

\section{Referências Bibliográficas}

ANGELUCCI, C. B., KALMUS, J., PAPARELLI, R. e PATTO, M.H.S. O Estado da Arte da Pesquisa sobre o fracasso escolar (1991-2002): um estudo introdutório. Educação e Pesquisa, vol. 30, n. 1, 2004, p. 51-72.

ANDERSON, G. e HERR, K. "The New Paradigm Wars: Is There Room for Rigorous Practitioner Knowledge in Schools and Universities?". Educational Researcher, Vol 28, nº 5, June/July 1999, 12-40. 
ANDRÉ, MARLI (org.) O Papel da Pesquisa na Formação e na Prática dos Professores. Campinas, SP, Papirus, 2002.

"A pesquisa sobre Formação de Professores no Brasil -1990/98. In Candau, V.M. (org.) Ensinar e Aprender: Sujeitos, Saberes e Pesquisa (ENDIPE). Rio de Janeiro, DP\&A, 2000,.257-266.

BEILLEROT, JACKY “A Pesquisa: esboço de uma Análise”. In MARLI ANDRÉ (org.) O Papel da Pesquisa na Formação e na Prática dos Professores. Campinas, SP, Papirus, 2002, 71-90.

CARVAlHO, M. "A Repetência e a Evasão da Escola Pública Fundamental nas Dissertações e Teses de Doutorado em Educação no Brasil". XXII Reunião Anual da ANPEd, Caxambu, MG, 1999, Anais Eletrônicos.

DAWSON, J. "Qualitative Research Findings: What do we do to improve and estimate their validity?" Trabalho apresentado no Encontro Anual da AERA, Nova York, 1982.

GATTI, B.A. Pós-graduação e pesquisa em educação no Brasil: 1978-1981. Cadernos de Pesquisa, N. 44, 1983, p. 3-17.

GATTI, BERNARDETE "A produção da Pesquisa em Educação no Brasil e suas Implicações Socio-Político-Educacionais: uma Perspectiva da Contemporaneidade". Trabalho apresentado na III Conferência de Pesquisa Sócio-cultural. Campinas, SP, julho de 2000, 20p.

LINCOLN, Y e GUBA, E. Naturalistic Inquiry, Newburg Park, CA, Sage, 1985.

MIRANDA, MARÍLIA G. "Ensino e Pesquisa na Formação de Professores: o Debate Contemporâneo sobre a Relação Teoria e Prática". Trabalho apresentado na IX Semana da Faculdade de Educação da UFGO. Goiânia, GO, agosto de 2000, $10 \mathrm{p}$.

STAKE, R.E. "The Case Study Method in Social Inquiry". Educational Researcher, vol $7, n^{\circ} 2,1978$.

WARDE, M. J. "O Papel da Pesquisa na Pós-graduação em Educação". Cadernos de Pesquisa, FCC, $\mathrm{n}^{\circ}$ 73, 1990, 67-75.

"A Produção Discente dos Programas de Pós-graduação em Educação no Brasil (1982-1991): Avaliação e Perspectivas". Avaliação e Perspectivas na Área de Educação 1982-91. ANPEd/CNPq, 1993. 